Deleuze, the concept of minor literature

and its unfolding in the Cortazarian machine

\title{
Deleuze, el concepto de literatura menor y su despliegue en la máquina cortazariana
}

\author{
Beatriz Elena Acosta Ríos \\ Magister en Estética, Universidad Nacional de Colombia, sede Medellín \\ Doctoranda en Filosofía y Ciencias del Lenguaje, Universidad Autónoma de Madrid \\ Docente investigadora de la Facultad de Artes y Humanidades, \\ Instituto Tecnológico Metropolitano, Medellín-Colombia \\ elenaacosta123@yahoo.com \\ DOI: http://doi.org/10.15366/bp2019.22.019 \\ Bajo Palabra. II Época. No 22. Pgs: 363-374
}


Recibido: 15/06/2016

Aprobado: 02/10/2019

\section{Resumen}

En este texto revisaremos el concepto de literatura menor, desplegado por Gilles Deleuze y Félix Guattari en su trabajo dedicado a la obra de Franz Kafka, en el que los filósofos logran delinear varias características propias de gran parte de la literatura contemporánea, que es expresión privilegiada de las condiciones sociales desde los tiempos del escritor checo hasta nuestros días. A partir de dicha revisión, rastrearemos las características de la literatura menor en la novelística cortazariana, entendida como una máquina literaria, deteniéndonos en Rayuela, novela que presentamos como dispositivo a la manera deleuziana.

Palabras clave: Deleuze, Literatura menor, dispositivo, Kafka, máquina literaria, Cortázar, Rayuela.

\section{Abstract}

In this text we will review the concept of minor literature, as deployed by Gilles Deleuze and Felix Guattari's work dedicated to Franz Kafka. These philosophers manage to outline several typical characteristics of contemporary literature, a privileged expression of social conditions from the time of the Czech writer to present day. From this review, we will trace the characteristics of minor literature from Cortazarian novels, thought to be a literary machine, while exploring Hopscotch, a novel we will present as a device in Deleuzian way.

Keywords: Deleuze, Minor literature, device, Kafka, literary machine, Cortázar, Hopscotch. 
$\mathrm{E}$ 1 nacimiento de Franz Kafka (1883) ocurre en las casi postrimerías del Imperio Austrohúngaro, en la ciudad de Praga, donde vivirá hasta su muerte (1924), pero su origen es judío; esa posición híbrida es fundamental en lo que luego él llamará literaturas menores. El nacimiento de Julio Cortázar en cambio (1914) se da en Bruselas poco después de que comenzara la Primera Guerra Mundial y su vida temprana estuvo marcada por los desplazamientos: de Bélgica a España y de allí a Argentina, país en el que además vivió su infancia en Banfield, en el sur de la provincia de Buenos Aires y desde 1951 hasta su muerte vivirá en París (1984). Con una considerable distancia geográfica e incluso temporal, la influencia del escritor checo en el argentino es sin embargo evidente en toda su obra, hecho que nos permite buscar en sus textos y en él mismo, rasgos de la literatura menor, con base en el despliegue que del concepto kafkiano hacen Gilles Deleuze y Félix Guattari en su libro Kafka por una literatura menor (1975).

Según Kafka, la condición de minoría en la literatura menor no depende de que haya sido escrita en una lengua menor, sino del uso menor de una lengua mayor, es decir, es la literatura de las minorías que habitan en ciudades donde se hablan lenguas hegemónicas y que se han visto impelidas a renunciar a sus lenguas vernáculas para sobrevivir; estos grupos se apropian las normas lingüísticas, deformándolas y enriqueciéndolas, construyendo día a día una lengua extranjera dentro de la lengua oficial. En esa lengua están escritas sus obras literarias, que entrañan la grieta originaria de sus escritores: es el caso de los judíos en Praga, pero también el de los negros en Estados Unidos y en general el de todos los inmigrantes, no solo extranjeros sino también connacionales de pueblos lejanos que se han desplazado a las capitales de sus países. Kafka habla alemán, el alemán de los judíos praguenses y en esa lengua escribe su literatura.

¿Qué características tiene la literatura menor? El 25 de diciembre de 1911 el escritor traza en su diario un esquema en el que señala como particularidades, entre otras, la elección de temas pequeños y la posibilidad de establecer sus propias reglas ${ }^{1}$, lo que de antemano nos sitúa frente a un tipo de creaciones que en ausencia de una larga tradición, puede inventarse y reinventarse según cada escritor, pero que precisamente por carecer de ortodoxia es más susceptible de conectarse con el

\footnotetext{
* Las ideas planteadas en este ensayo hacen parte de desarrollos parciales de la investigación que será presentada como la tesis doctoral titulada Deleuze-Cortázar. Lectura filosófica de Rayuela como novela-dispositivo.

1 Kafka, F., Diarios, Buenos Aires, Emecé, 1953, p. 143.
} 
pueblo en el que se origina y al que congrega, aunque ese pueblo no lo sepa, aunque esté aún por venir; esta literatura tiene por fuerza un carácter colectivo, es recibida por la multitud de solitarios que comparten el desarraigo con el escritor y hay camino expedito a su recepción, puesto que el lenguaje es sencillo, razón por la que ese pueblo la conservará, además es una literatura que habla de los hombres comunes y corrientes y de sus pequeñas historias. Como la pequeñez de ese pueblo no tiene que ver con su número de habitantes, es posible que la minoría se constituya en mayoría sin por ello dejar de estar en el margen de lo social (es de hecho el rumbo que ha tomado la historia en nuestro tiempo). Así, la literatura menor se convierte en el murmullo que la multitud susurra, en un canal regresivo a lo vernáculo, olvidado en apariencia pero vivo en los sustratos más profundos de la colectividad ${ }^{2}$. Había anotado Kafka ese mismo día de diciembre, en su diario:

La memoria de una nación pequeńa no es menor que la memoria de una grande, por lo tanto, puede digerir más a fondo el material transmitido. Es verdad que requerirá menos expertos en historia literaria, pero la literatura tiene menos que ver con la historia de la literatura que con el pueblo, y gracias a él se conserva con seguridad, aunque no con tanta pureza. Porque el conjunto de las exigencias de la conciencia nacional de un pueblo pequeńo sobre sus miembros aislados incluye la de estar preparado para conocer esa parte de la literatura que le ha sido transmitida, para mantenerla, y en todo caso para defenderla, aunque no la conozca ni la mantenga ${ }^{3}$

Deleuze y Guattari convierten el concepto kafkiano en una herramienta efectiva para el análisis de obras literarias que podemos considerar menores, puesto que se acercan a Kafka de una manera inédita, distanciándose de la crítica realizada hasta entonces, ya fuese desde perspectivas psicoanalíticas, hermenéuticas, religiosas o incluso estructuralistas. Los filósofos franceses no ven en la obra del escritor checo un exorcismo de su novela familiar, tampoco la expresión de una búsqueda religiosa, ni mucho menos la metaforización de las condiciones humanas de su tiempo; sino que plantean dicha obra como una máquina literaria, construida por un hombre para el que la vida entera era literatura. Ya Deleuze (1964) se había referido a Marcel Proust como el creador ex profeso de otra máquina literaria:

\footnotetext{
${ }^{2}$ Los cantos de los negros en Norteamérica constituyen el origen del blues y del jazz, al que Cortázar rinde homenaje en Rayuela: “[...] en Varsovia, en Milán, en Buenos Aires, en Ginebra, en el mundo entero, es inevitable, es la lluvia y el pan y la sal, algo absolutamente indiferente a los ritos nacionales, a las tradiciones inviolables, al idioma y al folklore: una nube sin fronteras, un espía del aire y del agua, una forma arquetípica, algo de antes, de abajo, que reconcilia mexicanos con noruegos y rusos y espańoles, los reincorpora al oscuro fuego central olvidado, torpe y mal y precariamente los devuelve a un origen traicionado [...]." Cortázar, J., "Capítulo 17", Rayuela, Madrid, Cátedra, 1994, p. 204.

3 Ibid., p. 142.
} 
Ya no se trata de una experiencia extraliteraria que el hombre de letras relaciona o de la que se aprovecha, sino de una experimentación artística producida por la literatura, de un efecto literario, en el mismo sentido que cuando se habla de un efecto eléctrico, electromagnético, etc. Proust es plenamente consciente de que el arte es una máquina de producir, y de producir principalmente efectos. Efectos sobre los otros, ya que los lectores o espectadores se pondrán a descubrir, en sí mismos y fuera de ellos, efectos análogos a los que la obra de arte ha sabido producir. ${ }^{4}$

La máquina literaria kafkiana está compuesta por diarios, cartas, cuentos y novelas y para comprender sus engranajes habría que considerarla en su totalidad: en las cartas produce un desdoblamiento subjetivo, entre sujeto de la enunciación (él) y sujeto del enunciado (su personaje), a través del que moviliza efectos en Felice (su principal destinatario-víctima), quien reacciona atendiendo a los llamados e interpelaciones en lo que respecta a sus consecuencias en la vida concreta, sin sospechar la manipulación que el escritor está haciendo de sus acciones, para él las cartas están circunscritas a los límites de los enunciados, sin por ello implicar al sujeto de la enunciación, habida cuenta del claro terror kafkiano a la conyugalidad y al yugo familiar ${ }^{5}$; por eso se entiende que Deleuze y Guattari vean en Kafka a un vampiro, cuyo combustible para la creación de los cuentos y las novelas, es la sangre que extrae de las $\operatorname{cartas}^{6}$. A su vez, los cuentos se presentan a los ojos de los filósofos como el paso siguiente, en el que ya no se corre el riesgo de comprometer al sujeto de la enunciación con consecuencias de lo enunciado por su personaje, ese Kafka-otro que habita en las cartas. En los cuentos hay ya un devenir animal, no como la representación de las acciones o de los sentimientos humanos a través de animales, es decir, como metáforas, sino como una captura efectiva y de carácter doble: el hombre captura del animal y el animal del hombre, se trata aquí de un cruce de fuerzas en el que el hombre implicado (personaje) deviene animal, todo en tiempo presente, en gerundio (pensemos en El buitre, La metamorfosis, Informe para una academia, etc). Los cuentos también pueden componer máquinas abstractas que tienen una funcionalidad dentro de la ficción pero que no consiguen engranarse en la máquina social, como ocurre en La colonia penitenciaria o en Preocupaciones de un padre de familia. En este segundo paso también se corren riesgos al no terminar: en el caso del devenir animal (que produce líneas de fuga), la re-edipización (por

\footnotetext{
${ }^{4}$ Deleuze, G., "Capítulo VIII. Antilogos o la máquina literaria”, Proust y los signos, Barcelona, Anagrama, 1995, p. 159.

5 La lectura de la correspondencia que sostuvo por varios ańos con su novia Felice cambia si se tienen en cuenta las anotaciones que el escritor hace en sus diarios justo los días en que escribe cada carta y que aclaran las búsquedas que esconden sus propuestas matrimoniales, sus prórrogas, sus demandas de afecto, sus llamadas de atención sobre supuestos estados de ánimo y sobre la necesidad de respuestas de ella, etc.

${ }^{6}$ También podemos hacer en esta dirección una relectura de la famosa Carta al padre.
} 
la resistencia a la fuga, la cucaracha-Samsa se deja ver por la hermana, quien la aplasta con una manzana) o la metaforización, y en el caso de la máquina abstracta (que aquí es una cosa), volverse infinito pues de lo contrario tendría que decantarse en novela. ¿Cuándo decide Kafka si un texto es cuento o novela? Sea cual sea la razón, esta no obedece a asuntos de mercado editorial. Los cuentos podrían ser experimentos, interludios entre novelas, o incluso novelas fracasadas, pero "aquí cada fracaso es una obra maestra, un tallo en el rizoma" 7 . Por último, las novelas constituyen dispositivos, pero no comprendidos como máquinas concretas, pues tienen de hecho un carácter de infinitud, de perpetuos aplazamientos, de paradójicas indeterminaciones; sino que es en esa constitución fragmentaria e incierta en la que se sostiene su consistencia: son como la vida, en ellas nada se resuelve o se resuelve a medias, los personajes no tienen claridad respecto a lo que les ocurre o a lo que hacen y hay un ruido constante, poblado de murmullos, de chismes, de malos entendidos, de palabras entrecortadas, de miradas soslayadas, de gestos contradictorios... Los filósofos entonces, encuentran lo más acabado de la obra kafkiana en las tres novelas: El desaparecido, El castillo y El proceso. Así, la máquina literaria proustiana se plantea como un dispositivo de aprendizaje a través de signos, con el que se crea el pasado mirando siempre hacia el futuro (también en este matiz invierte Deleuze las lecturas de la crítica al plantear una dirección de la mirada hacia el porvenir y no hacia lo pretérito): el pasado de Marcel en la novela monumental En busca del tiempo perdido no se presenta como un punto lejano y muerto al que el personaje regresa con un esfuerzo consciente de memoria, sino que viene a él en bloques de pasado puro a través de puertas sensibles que se abren y que constituyen signos por cuyas cuyas interpretaciones se aprende, hasta conseguir el aprendizaje final, en el momento en que el personaje empieza a escribir la gran obra, así recobra el tiempo al crearlo y consigue desplegar todos los regímenes sígnicos en la creación de signos artísticos en los cuales la vida entera confluye y para los que a su vez la vida se ofrece; gesto en el que se acercan Kafka y Proust: la vida como literatura. La máquina literaria kafkiana por su parte, alcanza su máxima expresión en los dispositivos novelísticos con base en los cuales el autor logra desmontar el dispositivo de la sociedad burocratizada de su tiempo y de los tiempos por venir: la actualidad de Kafka esa abrumadora en el estadio de las sociedades de control al que asistimos hoy, nuestra época es kafkiana.

La literatura menor tiene pues tres características: la escribe una minoría que experimenta un uso menor de una lengua mayor, todo en ella es político y todo tiene un valor colectivo. Nos hemos detenido en la primera y la tercera, de la segunda ya

\footnotetext{
Deleuze, G. y F. Guattari, "Capítulo 4, Los componentes de la expresión”, Kafka por una literatura menor, México D.F., Era, 1978.
} 
hablaremos. Por ahora preguntémonos: ¿`Podemos encontrar rasgos de la literatura menor en la obra cortazariana? O incluso: ¿’Podemos considerar a Cortázar un escritor menor en sentido kafkiano-deleuziano? Adelantemos la respuesta: sí. ¿Por qué?

La máquina literaria cortazariana está compuesta por cartas, entrevistas, cuentos, novelas, libros-miscelánea, collages, poesías, clases y ensayos. También constituye una madriguera, un rizoma, al que se puede entrar por cualquier lado y cuyas líneas se cruzan todo el tiempo, tal como ocurre con El perseguidor y Rayuela, con Rayuela y 62 modelo para armar, con Rayuela y el cuento El otro cielo, y un con largo etcétera de textos. Ahora bien, si comprendemos la máquina desde su carácter funcional, afirmaremos que la cortazariana se compone de dispositivos a través de los cuales podemos mirar el carácter fragmentario e incierto de la experiencia humana en la ciudad contemporánea; de ahí su permanente actualidad. La crítica ha hecho múltiples lecturas de esta máquina en todas las direcciones mencionadas a propósito de Kafka y de Proust (y también en otras), revisarla a través de los conceptos deleuzianos permite llamar la atención sobre la potencia de la obra es sí misma, movilizarla para efectos de desmontaje de dispositivos humanos (y urbanos) actuales.

Respecto a la primera característica de la literatura menor, Cortázar tiene una condición de minoría lingüística clara: va de Buenos Aires a París, donde escribe su obra en español y en francés, con una mezcla constante de estas dos lenguas, pero también con múltiples voces del lunfardo (uso menor del español entre la lunfa argentina, originaria de los bordes de la ciudad, en la orilla del Río de la Plata, donde se juntan italianos inmigrantes que poco a poco van asimilándose a la cultura rioplatense de forma poco pacífica y de cuyas tensiones sociales y existenciales darán cuenta las letras del tango, presentes en la literatura cortazariana). A su vez, Cortázar crea una lengua con fragmentos de unas ya existentes, valiéndose de la sonoridad de las palabras, ¿qué si no una lengua extranjera es el glíglico, ese lenguaje musical creado por y para los enamorados, que se ha emancipado de la dictadura del significante y del significado y que propende por un sentido hallado en efectos puros de superficie, en sensaciones? Proust había dicho: "Los libros hermosos están escritos en una especie de lengua extranjera. Bajo cada palabra cada uno de nosotros encuentra un sentido o al menos una imagen que a menudo es un contrasentido." ${ }^{8}$ Cortázar responde a su llamado: Rayuela está escrita en una suerte de lengua extranjera, no solo porque el escritor se inventa una lengua que inserta en la diégesis, sino porque en la totalidad de la novela tergiversa las normas ortográficas y gramaticales y mezcla varias lenguas. Sin embargo, el autor argentino no tiene que seguir la tarea propuesta por Deleuze y Guattari a propósito de la necesidad de buscar la lengua

8 Proust, M., "Apenas leía a un autor", Contra Sainte-Beuve: Recuerdo de una mañana, Madrid, Alianza, 2016, p. 283. 
extranjera en la propia en caso de haber nacido en un país en el que se hable una lengua mayor (esa tarea la había hecho Proust por ejemplo), puesto que él viene del Sur, de Buenos Aires, de Banfield, como los personajes de su novela, muchos venidos de países distintos, lo que tiene como consecuencia, no solo la complejidad de la lectura, sino, al interior de la historia, la incomprensión entre los mismos personajes, quienes al momento de entrar en la casa de Morelli para encontrar la novela que dejara el escritor moribundo, empiezan a hablar en sus lenguas vernáculas, indicio de lo que pasará luego: la separación del Club de la serpiente. Es decir: leemos una novela sobre una historia de amor que se termina sin concluir antes de la mitad del libro y sobre un grupo de amigos que se separan también antes del final y después, nos enfrentamos a la deportación del protagonista, a otros amores suyos y a su disolución hacia el final, sin que nos quede claro qué pasa con ninguno. No solo leemos una novela sobre personajes desterritorializados sino que asistimos a la desterritorialización misma de la novela en su sentido tradicional, pues la realidad del hombre contemporáneo ya no puede narrarse.

Con relación al segundo rasgo de la literatura menor, todo en ella es político porque la vida privada cede ante la intromisión de lo público, pues ya ninguna acción del individuo tiene consecuencias estrictamente individuales, sino que toda su vida se ve de repente influida por agentes externos, difusos, escurridizos, sin rostro claro, que sin embargo son omnipresentes; es lo que ocurre con Josef K. en el primer capítulo de El proceso, cuando de repente despierta rodeado de extrańos que lo detienen sin aclararle cuál fue su culpa y quienes incluso se comen su desayuno, a partir de ese momento la vida del personaje transcurrirá entre pasillos agobiantes, de puerta en puerta buscando su culpa, en un proceso que cada vez se prorroga más y en medio del cual se disuelve su privacidad de manera definitiva. A pesar de que en Rayuela no asistimos a esa burocratización de la vida cotidiana, por lo menos no de manera directa, los personajes principales (La Maga y Oliveira) en sus condiciones de inmigrantes (ella es uruguaya y él argentino) están expuestos a la pobreza y a la marginalidad y todo lo que dicen y viven está relacionado con esa situación, que fue a su vez la del escritor. Además, hay en la máquina literaria cortazariana un devenir político de facto (a diferencia de lo que ocurre con Kafka que se mantiene al margen de los movimientos anarquistas, aunque simpatice con ellos): el contacto con la Revolución Cubana in situ, luego de un viaje realizado a la isla en 1963 (año en que también se publica Rayuela), lo transforma y marca un punto de no retorno en su vida y en su trabajo, pues a partir de ese momento apoyará de manera explícita a los revolucionarios, no solo de Cuba, sino de Argentina e incluso de Nicaragua; ello le granjeará enemistades a los dos lados del Atlántico y el cuestionamiento de la calidad literaria de obras posteriores a Rayuela, sobre todo de El libro de Manuel 
(1973). Kafka murió sin ver morir a seres queridos suyos en campos de concentración nazis, víctimas de esas potencias diabólicas que desde su tiempo llamaban a la puerta. Cortázar sí vivió en carne propia las consecuencias de los totalitarismos y tomó partido en las luchas que en América Latina se llevaron a cabo contra las dictaduras, equivocado o no, creyó necesario pensar en una literatura que se inscribiera de manera directa en la política. Aunque esto ocurrió después de la publicación de Rayuela, podemos rastrear en la condición marginal de sus personajes los orígenes de una preocupación que desplegaría después.

Por último, tocante al valor colectivo que adquiere todo en la literatura menor, es claro que tanto para Kafka, cuanto para Deleuze, solo puede conectarse con el pueblo un solitario que desde el silencio de su habitación y su condición de minoría, encuentra la sintaxis para decir lo que ese pueblo necesita decir. De ahí la importancia de los devenires del escritor, puesto que en esos procesos de desterritorialización experimenta eso otro que entraña el pueblo (que no está constituido por una sumatoria de personas, sino que está encarnado en cada una: los dispositivos colectivos de enunciación hablan a través de cada uno de los que conforman el pueblo, cada uno es el pueblo entero). Así, Deleuze encuentra casos privilegiados de escritores de la desterritorialización en Melville, Hawthorne, Miller (no en vano le habla a Claire Parnet sobre la superioridad de la literatura angloamericana), pero también en Gombrowicz, Sacher-Masoch, Wolfson y por supuesto en Kafka. Nosotros encontramos a su vez en Cortázar ese carácter desterritorializado, ese devenir-otro constante que lo conecta con la colectividad de nuestro tiempo; rasgo que se expresa en cuentos como Axolot, Carta a una señorita en París, Cuello de gatito negro, Circe, Bestiario, Verano, Las babas del diablo o Las manos que crecen, en el que el personaje recorre la ciudad arrastrando entre sus dedos la basura de las calles (por citar solo algunos, aunque no podemos dejar de lado el devenir-otro de Johnny Carter en El perseguidor, quien al tocar su saxo encuentra múltiples líneas de fuga del mundo de las cronologías y que es el antecedente de Oliveira en la máquina literaria cortazariana). Ya en la novela, también vemos este rasgo en los encuentros sórdidos de Oliveira con la pianista decrépita Trépat y sobre todo con la clochard, pues en los bajos del Sena, el personaje desciende a lo más oscuro de lo urbano y de lo humano, ese capítulo 36 constituye en Rayuela un umbral de desterritorialización antes de que el personaje sea deportado a Buenos Aires, donde al final devendrá de forma incomprensible para el lector que asiste a un final sin final, en el que el devenir se impone al no resolverse ni en el punto de partida ni en uno de llegada (entre el capítulo 58 y el 131 la novela se queda rodando, en un infinito moebiano que, como la vida, no concluye). Desde esta perspectiva, la rayuela no es una metáfora de un libro para jugar o del juego en la vida, sino el eje de la máquina creada por Cortázar, 
en concreto de esta novela-dispositivo, en la que se muestra el acontecimiento de la vida sometido al más puro azar como si se tratase de un juego de niños, en el que nos pensamos libres, pero donde en el fondo estamos siendo jugados, aunque de todos modos el sentido de la vida también está en no dejar de jugar, en no parar el juego, dejar de jugar es morir, ya que solo en el juego de la rayuela se abren las líneas de fuga, las posibilidades de sacar la cabeza, de que las series proliferen; porque también para Cortázar, la vida es literatura. 


\section{REFERENCIAS BibLIOGRÁficas}

Cortázar, J., Cuentos Completos I y II, Madrid, Alfaguara, 1996.

Cortázar, J., Rayuela, Madrid, Cátedra, 1994.

Deleuze, G. y F. Guattari, Kafka por una literatura menor, México, Era, 1978.

Deleuze, G. y F. Guattari, Mil mesetas. Capitalismo y esquizofrenia, Valencia, Pre-Textos, 2004.

Deleuze, G., Diálogos, Valencia: Pre-Textos, 2013.

Deleuze, G., Proust y los signos, Barcelona, Anagrama, 1995.

Kafka, F., Diarios, Buenos Aires, Emecé, 1953.

Kafka, F., El proceso, Editado por Guillermo Sánchez, Medellín, Todográficas, 2015.

Proust, M., Contra Sainte-Beuve: Recuerdo de una mañana, Madrid, Alianza, 2016.

DOI: http://doi.org/10.15366/bp2019.22.019

Bajo Palabra. II Época. No 22. Pgs: 363-374 
